\title{
Contributions of detrital subsidies to aboveground spiders during secondary succession, revealed by radiocarbon and stable isotope signatures.
}

\section{$\operatorname{AUTHOR(S):~}$}

Haraguchi, Takashi F; Uchida, Masao; Shibata, Yasuyuki; Tayasu, Ichiro

\section{CITATION:}

Haraguchi, Takashi F ...[et al]. Contributions of detrital subsidies to aboveground spiders during secondary succession, revealed by radiocarbon and stable isotope signatures. Oecologia 2013, 171(4): 935-944

ISSUE DATE:

2013-04

URL:

http://hdl.handle.net/2433/173400

\section{RIGHT:}

The final publication is available at link.springer.com; この論文は出版 社版でありません。引用の際には出版社版をご確認ご利用ください。; This is not the published version. Please cite only the published version. 
1 Contributions of detrital subsidies to aboveground spiders during secondary succession, revealed by radiocarbon and stable isotope signatures

4

Tayasu $^{\mathrm{a}}$

${ }^{a}$ Center for Ecological Research, Kyoto University, 2-509-3 Hirano, Otsu, Shiga

520-2113, Japan

bNational Institute for Environmental Studies, 16-2 Onogawa, Tsukuba, Ibaraki 305-8506, Japan

Author Contributions: TFH designed the study as well as collected and prepared the samples for analyses, measured stable isotopes and performed statistical analyses. IT designed the study, as well as established and managed the sample preparation lines. MU and YS managed accelerator mass spectrometry and measured $\Delta^{14} \mathrm{C}$ isotope values. TFH wrote the first draft of the manuscript. All authors contributed substantially to revisions. 


\section{Abstract}

17 Subsidies from belowground originating from detrital sources add nutrients and energy

18 to arboreal communities. Measurement of this subsidy is required in the understanding

19 of how food web dynamics respond to changes in surrounding environments. Shrub

20 spiders are one of the key predators involved in food web coupling. We evaluate the

21 effects of potential changes in prey availabilities during secondary succession and how

22 different spider feeding guilds used the belowground prey subsidy. We measured the

23 relative importance of the subsidy for the spider feeding guilds, using $\delta^{13} \mathrm{C}, \delta^{15} \mathrm{~N}$ and

$24 \quad \Delta^{14} \mathrm{C}$ isotope measurements. Diet age was calculated from $\Delta{ }^{14} \mathrm{C}$ values, because old diet ages of spiders indicate the spiders are using prey from detrital food sources. Dominant aerial prey (Diptera) had a distinctively old diet age compared with arboreal prey, which indicates aerial prey was subsidized from detrital food webs. Sit-and-wait spiders tended to have an older diet age than active hunting spiders, which indicates that

29 sit-and-wait spiders depended more on subsidies. Diet age varied only slightly for spiders in stands of different ages, indicating that rates at which spiders use grazing and

31 detrital prey are probably determined more by foraging strategies and not by stand age.

32 A dominance of sit-and-wait predators will lead to higher detrital subsidy inputs to 33 shrub habitats. This study highlights the effect of shrub spider community structure 34 (feeding guild composition) on the volume of the subsidy received from belowground.

35 Key words: Aboveground-belowground linkage - Arboreal spider - Diet age · 36 Feeding guild $\cdot$ Mixing model 


\section{Introduction}

39 Most of the organic matter and energy input into food webs originally comes from plant

40 photosynthesis. Herbivores directly consume some photosynthetic products, leaving the balance of plant production to enter the soil as litter (Swift et al. 1979). Two sub-webs have been defined as the grazing and detrital sub-webs, based on the different pathways through which organic matter is supplied to the food web. These two sub-webs are spatially separated, because photosynthesis occurs aboveground and dead organic matter accumulates at the surface and belowground. However, the interlinking of the aboveground and belowground food webs is becoming widely acknowledged (Wardle et al. 2004; Bardgett and Wardle 2010). Prey-predator interactions, which are driven by the mixed diet of predators, are one of the linkages between the aboveground and belowground food webs. Several studies have shown predators often forage for a variety of prey that use different habitats and food sources (e.g. Vander Zanden and Vadeboncoeur 2002; Collier et al. 2002).

Spiders are one of the most dominant generalist predators in terrestrial ecosystems (Moulder and Reichle 1972; Settle et al. 1996). Miyashita et al. (2003) experimentally demonstrated spiders inhabiting shrub vegetation are subsidized by flying insects that have developed belowground, demonstrating that detrital subsidies have substantial contributions to aboveground food sources. Prey subsidy to shrub spiders has also been reported in an arable field (Von Berg et al. 2010), in a woodland

58 (Pringle and Fox-Dobbs 2008) and in a riparian zone (Akamatsu et al. 2004), implying shrub spiders can generally couple food webs in different habitats. 
61 biotic interactions, because plants provide habitats for other organisms, while providing

62 a baseline of energy and a living structural environment. Disturbance brings an abrupt 63 loss of biomass (Bormann and Likens 1979), mixes litter and woody debris with soils, 64 causes leaching of soil organic matter (SOM) and nutrients (Jurgensen et al. 1997), and 65 allows a subsequent reaccumulation process as the rate of production exceeds the community respiration rate (Kira and Shidei 1967). Also, the successional disturbance regime occurs repeatedly, which maintains the ecosystem's state of equilibrium (Bormann and Likens 1979). Therefore, comparing the contribution of prey subsidy between different ecosystems during succession helps to show how ecosystem changes affect donor control of shrub habitat in various environments. enhanced prey subsidy. Manipulative studies have shown the abundance of spiders is enhanced by the increased availability of prey from belowground, which occurred in response to the addition of detritus in both forest ecosystems (Chen and Wise 1999) and agroecosystems (Halaj and Wise 2002; Rypstra and Marshall 2005). These manipulative studies indicate that the community of spiders is under bottom-up control in various environments. Also, dipteran prey from soil, a dominant prey subsidy from belowground, occur at much higher densities in ecosystems with a well-developed litter layer compared with densities in grasslands or agroecosystems (Frouz 1999). Shimazaki and Miyashita (2005) compared the availability of a prey subsidy from belowground for

81 web-building spiders in shrubs, and showed the biomass proportion of aerial prey from 82 the detrital food web is higher in forests than in grasslands. These studies imply the 83 availability of belowground subsidy for spiders increases during forest succession, 
84 which may be caused by the reduced litter inputs after disturbance and recovery during succession (Lugo 2008).

Also, diets of spiders in different feeding guilds are thought to be different because of the differences in each guild's foraging methods. The foraging methods used by spiders, like their feeding guilds, are phyletically determined (Coddington and Levi 1991), with the different guilds and species using different food sources (Akamatsu et al. 2004; Birkhofer and Wolters 2012). Although previous studies have compared the feeding guild compositions of spider communities along successional gradients (Bultman and Uetz 1982), few studies have shown how spider feeding guilds respond to the changes in altered prey availabilities.

Stable isotope techniques have provided a continuous measure of the mass flows through ecological communities, and they have been used to quantify the relative contributions of each food source for various consumers. $\delta^{13} \mathrm{C}$ values have been used to detect food sources for consumers because trophic enrichment is $0.5 \%$ and much lower than $\delta^{15} \mathrm{~N}$ values. In contrast, the stable isotope signature of $\delta^{15} \mathrm{~N}$ has been used to assign organisms to trophic levels and feeding guilds, because trophic enrichment is higher for $\delta^{15} \mathrm{~N}$ than for $\delta^{13} \mathrm{C}$, which was 2.3\% for terrestrial animals (McCutchan et al. 2003). In addition to the trophic enrichment for $\delta^{13} \mathrm{C}$ and $\delta^{15} \mathrm{~N}$, another source of trophic enrichment is the process of decomposition. Decomposition with increased residence time tends to enrich the ${ }^{13} \mathrm{C}$ and ${ }^{15} \mathrm{~N}$ ratios of SOM (Michener and Lajtha 2007), and because detritivores use decomposed SOM as a food source, their $\delta^{13} \mathrm{C}$ and $\delta^{15} \mathrm{~N}$ values reflect the high $\delta^{13} \mathrm{C}$ and $\delta^{15} \mathrm{~N}$ values of those sources (Hishi et al. 2007). Therefore, enrichment through decomposition will result in higher $\delta^{13} \mathrm{C}$ and $\delta^{15} \mathrm{~N}$ content in prey 
107 from detrital food webs than in prey from grazing food webs. However, it has been

108 difficult to discriminate between the effect of trophic enrichment and enrichment

109 through decomposition.

110 Another isotope signature that can be used to trace food web structure is

111 radiocarbon $\left({ }^{14} \mathrm{C}\right)$, which allows direct estimation of the mean age of carbon. The

112 radiocarbon approach takes advantage of the elevated levels of ${ }^{14} \mathrm{C}$ in atmospheric $\mathrm{CO}_{2}$

113 that resulted from nuclear weapons tests in the early 1960s. Since the nuclear test ban

114 treaty of 1963, nuclear bomb-generated atmospheric ${ }^{14} \mathrm{C}$ in $\mathrm{CO}_{2}$ has exponentially

115 decreased (Levin and Hesshaimer 2000). Since we know the ${ }^{14} \mathrm{C}$ content of organic

116 matter synthesized by primary producers is the same as that of atmospheric $\mathrm{CO}_{2}$ at the

117 time of production (Burchuladze et al. 1989; Druffel and Griffin 1995), we can estimate

118 the diet age of consumers, which is defined as the mean time elapsed since $\mathrm{C}$ in the

119 consumer's diet was fixed from atmospheric $\mathrm{CO}_{2}$ by primary producers. After the

120 seminal study by Tayasu et al., (2002), Hyodo et al. (2006) showed consumers in a

121 grazing food web had a relatively new diet age of $0-4$ years, while termites, which

122 consume detrital foods, had an older diet age of a maximum of 18 years. Diet age,

123 which is estimated from $\Delta^{14} \mathrm{C}$ (bomb-carbon), distinguishes the grazing and the detrital

124 sub-webs, and should give information about the coupling process between the two

125 sub-webs (Tayasu and Hyodo 2010).

126 In this study, using the diet age of the spiders as a measure to detect prey 127 subsidy from detrital food webs, we reveal the dynamics of forest food webs during 128 forest succession. Also, using stable isotopes, we estimate the contribution rates of each 129 prey group by taxonomic order and body length for shrub spiders, and we test the 
130 following hypotheses. First, the prey subsidy from the detrital food web will have

131 distinctively old diet ages compared with prey from the grazing food webs. Second, if

132 spiders segregate their food sources by feeding guild in every stage of forest succession,

133 the diet ages of spiders will be older in highly subsidized guilds. Third, we hypothesize

134 that if spiders mainly determine their prey based on prey availability, then the prey that

135 are subsidized from belowground will contribute much more to spiders in late

136 successional forest and older diet ages will appear in spiders from old growth forests.

\section{Materials and methods}

\section{Study site}

140 The study sites are located in and near the Ogawa Forest Reserve (OFR) at the southern

141 edge of the Abukuma Mountains, northern Ibaraki Prefecture, in central Japan

142 (approximately $36^{\circ} 56^{\prime} \mathrm{N}, 140^{\circ} 35^{\prime} \mathrm{E}, 580-800 \mathrm{~m}$ a.s.1.). The mean annual temperature in

143 Ogawa from 1986 to 1995 was $10.7^{\circ} \mathrm{C}$ (Mizoguchi et al. 2002). The mean annual

144 precipitation is about $1900 \mathrm{~mm}$. Clear-cutting of natural forest for pulp production is

145 continuing around the OFR, and secondary forests of different stand ages are available.

146 We selected four $50 \times 50 \mathrm{~m}^{2}$ plots within $6 \mathrm{~km}$ of the OFR; the fifth site with the oldest

147 trees was the only one on OFR lands. Stand ages were 1, 7, 11, 24 and 105 years at the

148 five sites, based on forest administration department records. Each plot was at least 20

$149 \mathrm{~m}$ from the stand edge to avoid lateral inputs from adjacent environments.

\section{Sampling and identification}

152 Sampling was conducted from Jul- to Oct-2008 and from Jun- to Jul-2009. Fresh leaves 
153 collected in Jul-2008 were used to determine the $\Delta^{14} \mathrm{C}$ values for organic carbon fixed

154 from $\mathrm{CO}_{2}$ during 2008 at the study sites. We selected abundant trees species from both

155 the canopy and the understory (less than $2 \mathrm{~m}$ tall) and sampled from three ramets

156 (Appendix S1). However, younger age stands (1 and 7 years) were mostly comprised of

157 trees $<5 \mathrm{~m}$ tall. Then we sampled fresh leaves from abundant tree species, which were

158 categorized as canopy trees. In older age stands, fresh leaves were collected from $\sim 10 \mathrm{~m}$

159 above the ground. We dried these fresh leaves at $60^{\circ} \mathrm{C}$.

160 We used two methods to sample arthropods and grouped them accordingly. For

161 sweep net sampling (sweeping) we used nylon mesh nets $30 \mathrm{~cm}$ in diameter by 162 sweeping from $0.5 \mathrm{~m}$ to $2 \mathrm{~m}$ aboveground. We categorized prey samples caught by this

163 method as aerial prey. We also beat shrubs to up to $2 \mathrm{~m}$ aboveground and collected

164 fallen insects (beating). We categorized prey samples caught by this method as arboreal

165 prey. We stored samples for isotopic analyses in screw vials at room temperature for

166 more than 48 hours, allowing them to excrete gut contents. We washed the samples with

167 distilled water and then freeze-dried them.

168 We separated the prey samples into six fractions based on taxonomic order and

169 body length to measure isotopic values. Because the biomass of individuals varied

170 widely, mixing entire samples of one taxonomic order would result in a predominance

171 of large individuals for mass ratio calculations. However, it is unreasonable to consider

172 larger prey as important food sources, because spiders have optimal prey sizes that

173 depend on the preferences and abilities of each spider species, such as the size of an orb

174 web (Brown 1981). Therefore, before mixing prey samples, we measured body length

175 of all prey under a stereomicroscope and separated dominant prey orders into three size 
176 classes: $0-5 \mathrm{~mm}, 5-10 \mathrm{~mm}$, and $>10 \mathrm{~mm}$ body length. Diptera dominated aerial prey in

177 every size class, while the dominant order of arboreal prey differed in each size class.

178 Consequently, we decided to measure isotope ratios of prey that were grouped in three

179 size categories for Diptera. We did the same for dominant arboreal prey by size class as

180 follows: Collembola (dominant in the $0-5 \mathrm{~mm}$ arboreal prey size class), Hemiptera (5-

$18110 \mathrm{~mm})$, and larvae of Lepidoptera $(>10 \mathrm{~mm})$. We mixed at least three individuals for 182 each prey sample.

183 Spiders were identified to species using morphological traits. We analyzed

184 individual spiders as long as individual masses provided enough material to accurately

185 measure isotopic values, so intraspecific and interspecific differences could be 186 compared. For two spider species (Leucauge subblanda Bösenberg et Strand 1906 and

187 Yaginumaella striatipes (Grube 1861)), we measured isotope ratios of multiple 188 individuals to document the variations of isotope values for these two species. We 189 categorized spiders into four feeding guilds, visual pursuit, nocturnal hunting, orb web

190 and crab spiders, based on foraging strategies of the taxonomic families of those spiders.

191 Both visual pursuit and nocturnal spiders forage by actively searching for prey, but

192 visual pursuit spiders find prey by eyesight, while nocturnal spiders find prey at night, 193 apparently by sensing vibrations. Both orb web and crab spiders forage for prey using a

194 sit-and-wait strategy, but orb web spiders catch prey using orb webs, and crab spiders

195 catch prey by using their extended anterior limbs. Appendix S2 contains details about 196 the spider samples.

197 


\section{Isotope analyses}

199 We measured stable isotope ratios (\%) using an EA1108 elemental analyzer (Fisons

200 Instruments, Milan, Italy) connected to a Delta S mass spectrometer (Finnigan MAT,

201 Bremen, Germany) with a Conflo II interface (Finnigan MAT, Bremen, Germany). We

202 corrected data with international standard substances (Tayasu et al. 2011). Standard

203 deviations of the measurements of $\delta^{13} \mathrm{C}$ and $\delta^{15} \mathrm{~N}$ were $0.10 \%$ and $0.09 \%$, respectively.

$204 \delta^{13} \mathrm{C}$ and $\delta^{15} \mathrm{~N}$ signatures are reported as relative to carbonate in Vienna Pee Dee

205 Belemnite for atmospheric carbonate and nitrogen, respectively, using the following

206 equation:

$207 \delta^{13} \mathrm{C}$ or $\delta^{15} \mathrm{~N}(\%)=\left(R_{\text {sample }} / R_{\text {standard }}-1\right) \times 10^{3}$

$R={ }^{13} \mathrm{C} /{ }^{12} \operatorname{Cor}{ }^{15} \mathrm{~N} /{ }^{14} \mathrm{~N}$

209 We performed graphitization for radiocarbon $\left({ }^{14} \mathrm{C}\right)$ measurement following the

210 method of (Kitagawa et al. 1993). We measured ${ }^{14} \mathrm{C}$ concentrations using an accelerator

211 mass spectrometer (AMS, National Electrostatics Corp., Middleton, WI, USA) in the

212 National Institute for Environmental Studies following the method of Uchida et al.

213 (2004) and reported it as a $\Delta^{14} \mathrm{C}$ value. The following equation defines $\Delta^{14} \mathrm{C}$ :

$214 \quad \Delta^{14} \mathrm{C}(\%)=\delta^{14} \mathrm{C}-2\left(\delta^{13} \mathrm{C}+25\right)\left(1+\delta^{14} \mathrm{C} / 1000\right)$

We corrected ${ }^{14} \mathrm{C}$ concentrations for the ongoing radioactive decay of the

216 international reference standard (oxalic acid) since AD 1950 and corrected for $\delta^{13} \mathrm{C}$

217 signatures of $-25 \%$ (Stuiver and Polach 1977). Owing to the correction applied for ${ }^{14} \mathrm{C}$

218 concentrations, fractionations of ${ }^{14} \mathrm{C}$ were cancelled by the use of $\delta^{13} \mathrm{C}$ values, when

219 represented by $\Delta^{14} \mathrm{C} . \Delta^{14} \mathrm{C}$ signatures were reported with an error (\%o) for each analysis, 
which was within $5 \%$ ( $2.8 \%$ on average).

221

\section{Source contribution estimation and diet age estimation}

223 For whole prey samples, we compared $\delta^{13} \mathrm{C}$ and $\delta^{15} \mathrm{~N}$ between arboreal and aerial prey

224 to test how arboreal and aerial prey sources could be distinguished isotopically. Then,

225 we estimated the contribution of each aerial prey relative to the entire group of prey 226 using a dual isotope $\left(\delta^{13} \mathrm{C}\right.$ and $\left.\delta^{15} \mathrm{~N}\right)$ MixSIR (ver. 1.0.4) model (Moore and Semmens 227 2008; Semmens et al. 2009). We defined each source category based on the order of the 228 prey and used four sources to estimate contribution rates. We set trophic enrichment of $229 \delta^{13} \mathrm{C}$ and $\delta^{15} \mathrm{~N}$ in the modeling to $0.5 \pm 1.37 \%$ and $2.3 \pm 1.52 \%$ (mean \pm standard 230 deviation), respectively, using the value for terrestrial animals reviewed by McCutchan 231 et al. (2003). For the analyses of contribution rates of aerial prey, medians of the contribution rates were used.

We estimated the diet age using the following method. First, $\Delta^{14} \mathrm{C}$ of

234 atmospheric $\mathrm{CO}_{2}$ was estimated to be exponentially decreasing (Eq. 4; Hyodo et al. 235 2006):

236

237

$\Delta^{14} \mathrm{C}(t)=417 \times \exp \{(1974-t) / 16\}$

238 where $t$ is represented in dominical year.

239 We made some modifications to Eq. 4 because the $\Delta^{14} \mathrm{C}$ value of local $\mathrm{CO}_{2}$ was

240 determined by the mixing of two sources. One of the sources follows the globally

241 observed trend expressed in Eq. 4, and another source is $\mathrm{CO}_{2}$ that originated from fossil

242 fuel, of which the $\Delta^{14} \mathrm{C}$ value is almost constant $(-1000 \%)$. We assumed the rates of 
$243 \mathrm{CO}_{2}$ from local fossil fuel combustion in atmospheric $\mathrm{CO}_{2}$ were constant through time

244 and denoted by $P$ in the following equations:

$245 \quad \Delta^{14} \mathrm{C}_{\text {sample }}=(1-P) \times \Delta^{14} \mathrm{C}(t-D)-1000 \times P$

$246 \Delta \Delta^{14} \mathrm{C}_{\text {sample, }} t$ and $D$ indicate any $\Delta{ }^{14} \mathrm{C}$ value of samples obtained from a single site that

247 originate from locally photosynthesized organic matters, sampling year and diet ages,

248 respectively. From Eq. 4 and Eq. 5, we can calculate $D$ from Eq. 4 and 5, for given $P$ :

$D=T+16 \times\left\{\ln \left(\left(\Delta^{14} C_{\text {sample }}+1000 \times P\right) /(1-P)\right)-\ln 417\right\}-1974$

250 We obtained foliar samples, which are thought to show $\Delta^{14} \mathrm{C}$ values of local

251 atmospheric ${ }^{14} \mathrm{CO}_{2}$ concentrations during the sampling period $t$ (equals 2008.7, in this

252 study). Therefore, when $\Delta^{14} \mathrm{C}_{\text {sample equals foliar }} \Delta^{14} \mathrm{C}$ values, $D$ equals 0 . By substituting

253 the values, we solved Eq. 6 for $P$ at each study site and calculated diet ages of all other

254 samples.

255

256 Statistical analyses

257 We applied two-way analysis of variance (ANOVA) to test whether or not each study

258 site (1-, 7-, 11-, 24-, 105-year-old forest sites) and each category of samples (shown in

259 parentheses below) are the determinants of foliar $\Delta^{14} \mathrm{C}$ (canopy and understory tree

260 leaves), diet ages of prey (arboreal and aerial prey), and diet ages of two species of

261 spiders (L. subblanda and Y. striatipes), which were repeatedly measured for their $\Delta^{14} \mathrm{C}$

262 content. We applied one-way ANOVA to test $\delta^{13} \mathrm{C}$ and $\delta^{15} \mathrm{~N}$ values of aerial versus

263 arboreal prey as separate source values. We created a generalized linear mixed model

264 (GLMM) to analyze the relationships between diet ages of individual spiders and 
265 feeding guild of the spiders and the change in food sources during secondary forest

266 succession. The full model included the following explanatory variables: stand age as a

267 continuous variable and the feeding guild of spiders as a categorical variable. We also

268 incorporated spider species as a random and categorical variable into the full model. For

269 the GLMM analysis, the Akaike information criterion (AIC) least model was selected as

270 the best fit model to explain diet ages of spiders. All the statistical analyses were

271 conducted by R version 2.13.0 (R development core team 2011). Package "Ime4" was

272 used for GLMM analysis.

\section{Results}

\section{Stable isotope ratios of prey and spiders}

276 Overall means and standard deviations of carbon and nitrogen stable isotope ratios for aerial prey were $-25.6 \pm 0.8$ and $4.5 \pm 1.8 \%$, whereas the values for arboreal prey were $-29.2 \pm 1.9$ and $-1.8 \pm 1.9 \%$. Carbon and nitrogen isotope ratios of aerial prey were significantly different from arboreal prey (one-way ANOVA, $F_{1,56}=43.4, P<0.001$ for $\delta^{13} \mathrm{C}$ and $F_{1,56}=117, P<0.001$ for $\left.\delta^{15} \mathrm{~N}\right)$, and the food sources were clearly separated

281 by the differences in isotope signatures between aerial prey and arboreal prey (Fig. 1).

282 Carbon and nitrogen isotope ratios, which were offset for trophic enrichment, were 283 located within polygons of the stable isotopes biplots of the four prey categories in each 284 study site, indicating the source mixing models can be applied.

The MixSIR source mixing model generated variable contribution rates of aerial prey, which had a median from 0.11 to 0.68 (from minimum to maximum). The

287 high variation of the contribution rate was accounted for by the wide range of carbon 
and nitrogen isotope ratios of spiders, even within a single site.

289

\section{Plant $\Delta^{14} \mathbf{C}$ as a basis for diet age calculation}

291 The $\Delta^{14} \mathrm{C}$ values of canopy leaves and understory leaves were $43.0 \pm 6.4$ and $46.2 \pm$

$2925.8 \%$ (mean \pm standard deviation), respectively (Fig. 2a). The $\Delta^{14} \mathrm{C}$ of leaves were significantly different between study sites but not between canopy trees and understory trees (two-way ANOVA, $F_{4,18}=3.3, P=0.034$ for study sites and $F_{1,18}=1.3, P=0.26$ for canopy or understory trees). Thus, we used mean values of each study site as the $\Delta^{14} \mathrm{C}$ value of current production, shown as foliar $\Delta^{14} \mathrm{C}$ in Eq. 6.

Diet ages of prey and spiders

299 Diet ages of aerial prey (Diptera) were always older than those of arboreal prey

300 (Collembola, Hemiptera, larva of Lepidoptera) at any stand age, excluding one case (Fig.

3013 ) where the Diptera of size class $5-10 \mathrm{~mm}$ was $1.5 \%$ lower in $\Delta^{14} \mathrm{C}$ value than

302 Hemiptera at the 105-year site, which was within the precision of the AMS. The diet ages of aerial prey were significantly older than arboreal prey, but the measurements between the study sites were not significantly different (two-way ANOVA, $F_{1,24}=62.1$, $P<0.001$ for prey category and $F_{4,24}=0.7, P=0.60$ for study sites).

Two spider species were repeatedly measured in nearly every study site. The

307 first, L. subblanda, an orb web spider, had a diet age of $6.5 \pm 1.9$ years. The second, $Y$.

308 striatipes, a visual pursuit predator, had a diet age of $3.6 \pm 2.3$ years (Fig. 2b). $Y$.

309 striatipes was not collected in the 1- and 7-year-old sites. Diet age was significantly

310 different between spider species, but was not significantly different between study sites 
311 (two-way ANOVA, $F_{1,16}=12.5, P=0.0028$ for species and $F_{4,16}=2.01, P=0.14$ for 312 study sites).

313 Diet ages of all spiders were within the ranges between minimums and

314 maximums of diet age of prey, excluding one study site (Fig. 3). Simple linear

315 regression revealed spider diet age increased when increasing proportions of aerial prey

316 were used as a food source (adjusted $r^{2}=0.08, P=0.03$ ). This correlation corresponds

317 to the positive correlation between diet age and the $\delta^{13} \mathrm{C}$ value (adjusted $r^{2}=0.28, P<$

3180.001 ), and the positive correlation between diet age and the $\delta^{15} \mathrm{~N}$ value (adjusted $r^{2}=$

$3190.11, P=0.009$ ) for spiders (Fig. 4).

320 Feeding guild factored in with the random effect of species was selected as the 321 least AIC model $(\mathrm{AIC}=237, \mathrm{df}=6$, whereas the full model was $\mathrm{AIC}=244, \mathrm{df}=7)$ in

322 the GLMM analysis. The estimated diet ages, with the standard error, by feeding guild

323 for visual pursuit, nocturnal, orb web and crab spiders were $1.2 \pm 2.1,3.5 \pm 1.5,5.5 \pm$ 3241.8 , and $5.7 \pm 2.5$ years, respectively. The factor based on stand age, measured as years 325 after clear-cutting, was not selected during the AIC model selection.

\section{Discussion}

\section{Source mixing models using $\delta^{13} \mathbf{C}$ and $\delta^{15} \mathbf{N}$}

$329 \delta^{13} \mathrm{C}$ and $\delta^{15} \mathrm{~N}$ values of the aerial prey (Diptera) were higher than those of the arboreal 330 prey by $3.5 \%$ and $6.0 \%$ on average, respectively. One of the possible reasons for the 331 higher $\delta^{13} \mathrm{C}$ and $\delta^{15} \mathrm{~N}$ values for aerial prey is that aerial prey were dominated by 332 predators, which would be expected to naturally have higher $\delta^{13} \mathrm{C}$ and $\delta^{15} \mathrm{~N}$ values.

333 However, it is very unlikely that Diptera forage for arboreal prey for which isotope 
334 ratios were measured in this study, because this hypothesis assumes a high ${ }^{13} \mathrm{C}$

335 enrichment at each trophic level. Another more convincing possibility is that the 336 increase in $\delta^{13} \mathrm{C}$ and $\delta^{15} \mathrm{~N}$ values for aerial prey is caused by the fact their food 337 originates from decomposed litter. ${ }^{13} \mathrm{C}$ and ${ }^{15} \mathrm{~N}$ enrichment through decomposition has 338 been generally observed (Michener and Lajtha 2007; Hishi et al. 2007).

\section{Diet age estimation from $\Delta^{14} \mathbf{C}$}

341 Previous studies reported site-specific $\Delta^{14} \mathrm{C}$ signatures of current year photosynthetic

342 production among sites and attributed the variations to anthropogenic $\mathrm{CO}_{2}$ emissions

343 (Shibata et al. 2005; Pataki et al. 2010). These studies indicate it is necessary to consider

344 the local atmospheric ${ }^{14} \mathrm{CO}_{2}$ variations caused by anthropogenic carbon dioxide

345 emissions, which fluctuate at a local scale when comparing $\Delta{ }^{14} \mathrm{C}$ values between sites.

346 Our results indicate the difference in $\Delta^{14} \mathrm{C}$ values was about $10 \%$ between the study

347 sites, which is equivalent to a shift of 3-4 years in diet ages since 2008. In contrast,

$348 \quad \Delta{ }^{14} \mathrm{C}$ values between canopy and understory leaves were not significantly different (Fig.

349 2a). Therefore, in this study, the concentration of $\mathrm{CO}_{2}$ originating from fossil fuel is

350 shown to differ between study sites, while the $\mathrm{CO}_{2}$ was homogenized vertically at any

351 single site. We made modifications to the equation related to diet age and $\Delta^{14} \mathrm{C}$ value

352 (Eq. 7) to calibrate the variations of the $\Delta^{14} \mathrm{C}$ values of currently photosynthesized 353 organic matter between study sites.

\section{Diet ages of prey}

356 Diet ages of aerial prey were always older than those of arboreal prey (Fig. 3). The 
357 maximum diet ages of prey in each study site were 8 to 12 years and the prey were all

358 Diptera (Appendix S3). Hyodo et al. (2006) showed older diet age (5 to 18 years)

359 appeared only in detritivores (termites), whereas a younger diet age (0 to 4 years)

360 appeared in herbivores (bees); thus diet age provides a tool in understanding both

361 terrestrial grazing and detrital food webs as well as in understanding the interactions

362 between these two. Old diet ages of aerial prey (Diptera) in our study indicate the

363 dominant prey in aerial habitats were detritivores. Considering most Dipterans originate

364 from soil (Frouz 1999) and soil ecosystems are a major part of the detrital food web, the

365 old diet age of dominant aerial prey indicates the prey is subsidized from the

366 belowground detrital food web.

367

These findings are consistent with the results of $\delta^{13} \mathrm{C}$ and $\delta^{15} \mathrm{~N}$ values of aerial

368 prey, indicating they originated in the detrital food web. Decomposition with increased

369 resident time tends to enrich ${ }^{13} \mathrm{C}$ and ${ }^{15} \mathrm{~N}$ ratios of SOM. Hyodo et al. (2008) indicated a

370 positive correlation exists between $\delta^{15} \mathrm{~N}$ values and diet ages of detritivores

371 (earthworms and termites), and also indicated humigated organic matter is enriched with

$372{ }^{15} \mathrm{~N}$, confirming the ${ }^{15} \mathrm{~N}$ enrichment along a humification gradient (Tayasu 1998). Also,

$373{ }^{13} \mathrm{C}$ in SOM is enriched with increasing depth (Michener and Lajtha 2007), which 374 indicates ${ }^{13} \mathrm{C}$ is also enriched during the decomposition process. High ${ }^{13} \mathrm{C}$ and ${ }^{15} \mathrm{~N}$ ratios 375 and old diet ages of aerial insects are all consistent with the hypothesis that their food 376 sources are derived from detrital material.

377 Diet ages of some arboreal prey were negative (Fig. 3). This indicates arboreal 378 prey consumed more recently photosynthesized fractions than whole plant leaves. A 379 reasonable assumption is that a sizable percentage of the leaves consumed by the prey 
species, that is, leaves made of structural substances such as cellulose and lignin

381 (Kirschbaum and Paul 2002), is derived from older photosynthesized carbohydrates

382 rather than labile fractions, such as glucose and lipids. Studies on resource allocation for

383 growth and reproduction of perennial plants have shown plants have the ability to store

384 previously photosynthesized organic matter (Sork et al. 1993), and such storage can be

385 allocated to leaves especially during leaf formation. These results suggest extracting the

386 labile fraction of plants for estimating the current $\Delta{ }^{14} \mathrm{C}$ values may be more suitable, but

387 selecting the "most appropriate" fraction that represents most recently-fixed carbon

388 seems to be a topic for another study. Therefore, we concluded it was a practical option

389 to assume $\Delta{ }^{14} \mathrm{C}$ of whole plant leaves approximately represents the $\Delta^{14} \mathrm{C}$ values of organic matters of current production.

The maximum diet age of arthropods in each site was 8 to 12 years (Appendix

392 S3). Such old diet ages suggest organic matter was retained in the detrital pool as

393 biologically available fractions in every successional stage. This may be specific to

394 areas undergoing secondary succession after clear-cutting, which release large amounts

395 of dead organic matter into forest stands. Thus, an old diet age in a young timber stand

396 indicates dead organic matter released by disturbance comprises important energy

397 sources for food webs in early successional stages, such as a clear-cutting type of

398 disturbance. Further studies will be required to reveal how quality and quantity of

399 residuals will differentiate food web structures between differently disturbed 400 ecosystems. 


\section{Diet ages of spiders}

403 The $\Delta^{14} \mathrm{C}$ values for almost all spiders were within the range of the $\Delta^{14} \mathrm{C}$ values of prey 404 at each site (Fig. 3). This indicates our sampling covered potential food sources for 405 spiders. The diet ages of spiders are positively correlated with the relative contribution 406 rate of aerial prey, which have an older diet age than arboreal prey (Fig. 4). This 407 indicates the diet age of spiders increases with an increasing the contribution rate from 408 the predation of aerial insects, suggesting greater prey subsidies from belowground.

409 Differences in diet ages between the two spider species were found (Fig. 2b), 410 although diet age was difficult to measure repeatedly for all spiders because of the time 411 and expense required to do $\Delta^{14} \mathrm{C}$ analysis. However, this study documents how 412 species-specific differences in foraging behavior affected food utilization and, as a 413 result, changed the dependency on detrital subsidies. The two species compared in this 414 study were L. subblanda, an orb web spider, and Y. striatipes, a visual pursuit spider. 415 The fact that diet age of an orb web spider species was older than a visual pursuit spider 416 species suggests the orb web spider's diet depended more on the detrital food web than 417 did the diet of visual pursuit spiders.

418 Notably, the difference in diet age among the study sites was relatively small, 419 and no trend along the forest successional gradient was seen (Fig. 2b). GLMM analyses 420 of the all spiders revealed diet ages of spiders were explained by their categories of 421 feeding guilds, but stand age as a variable did not explain the diet age variation. This 422 indicates the feeding guild of spiders affects the contribution rate of prey from the 423 detrital food web, while environmental variations along successional lines only weakly 424 influence the prey utilization of spiders. The results of the GLMM analysis also agrees 
with the comparison of diet ages between two species (L. subblanda and Y. striatipes), in that feeding guilds of spiders, not the differences among study sites nor stand age of

427 the sites, affected the contribution rates of the detrital and grazing food sources. This

428 indicates arboreal spiders tend to specialize and consume a specific prey fraction to

429 some degree and more than previously thought. That is, some preferred aerial prey,

430 which mainly emerged from belowground, while others concentrated on arboreal prey,

431 which mainly inhabited aboveground. This suggestion is surprising, considering that the

432 availability of the two prey categories will increase during succession. Furthermore, orb

433 web and crab spiders had a tendency to have an older diet age than nocturnal and visual

434 pursuit spiders. The former two spiders take a sit-and-wait strategy, while the latter two

435 spiders actively hunt. Considering both the major prey subsidy from detrital food webs

436 and aquatic food webs were aerial insects, studies for prey subsidy from aquatic

437 ecosystems are comparable with our results. Akamatsu et al. (2004) documented the

438 tendency for cursorial spiders to have a lower subsidy of aquatic insects than

439 web-building spiders. Henschel et al (2001) compared diets of an orb weaving spider

440 species and a nocturnal species and showed that increases in aquatic prey availability

441 affected differently on the two species. The relative contributions of aquatic insects

442 were higher at a stream edge for both two spiders than at $30 \mathrm{~m}$ from the edge; the rate of

443 increase was higher for the orb weaving spiders. These studies for aquatic prey subsidy,

444 together with our results suggest the sit-and-wait spiders favor foraging active prey, the

445 movement of which drive prey subsidy to spiders. Also, our results show the method of

446 foraging of each spider feeding guild can have more influence than the differences in

447 availabilities of subsidized prey which is determined by the surrounding environments. 
These results indicate that feeding guild composition is an important factor

449 affecting food sources for spider communities. Our study reveals the diet ages of spiders

450 range from 0.11 to 0.68 (from minimum to maximum), including all individuals, and

451 confirms a high level of variation exists in the relative contributions of Diptera, based

452 on the MixSIR model. This variation indicates the amount of belowground subsidy assimilated by the shrub spider community can vary widely, based on one extreme condition, dominance of spiders that are least subsidized, and the other extreme condition, dominance of spiders that are most subsidized.

Previous studies have shown the importance of belowground subsidy in generating an abundance of spiders (Chen and Wise 1999; Rypstra and Marshall 2005) or for a specific feeding guild of spiders (for orb web spiders; Miyashita et al. 2003). However, the quantitative importance of the subsidy has never been compared between different environments across multiple feeding guilds because of the difficulty in

461 quantifying food sources that originate belowground. Food web analyses using isotope 462 measurements enabled us to compare the importance of each food source between 463 different feeding guilds and to develop our understanding about each feeding guild's consumption of prey that originated in belowground environments. Shrub spiders segregate their food sources by feeding guild and showed a consistent tendency in the

466 mixing rate of prey from belowground and aboveground within guilds. We also found a

467 stronger effect was generated by the way spiders forage for their diets rather than by the 468 availabilities of prey in surrounding environments. Results from this study suggest the 469 relative abundance of sit-and-wait spiders during forest succession is one of the 470 determinants of the subsidy rate for the shrub spider community. To our knowledge, this 
471 is the first study to propose the importance of predator community composition in

472 determining the rate of belowground subsidy.

473 One question that still needs to be answered is whether changes in spider

474 community composition during succession will alter a food web in terms of the amount

475 of input from belowground. Our study implies conditions in late successional forest

476 favor sit-and-wait predators, through the enhancement of subsidy from belowground.

477 Several studies documented changes in guild compositions of spiders during forest

478 succession (Bultman and Uetz 1982) and the existence of relationships between guild

479 compositions and surrounding environments (Uetz et al. 1999), although impacts of the

480 compositions on their use of subsidy were not known. To answer this question, both the

481 dynamics of the spider community and the food sources for each species need to be

482 determined. Further study using both isotope measurements and spider community 483 analyses will reveal what changes in predator community composition during 484 succession affect their function as a driver of food web coupling.

\section{Conclusions}

487 This study reveals the extent of prey subsidy for predators in forest shrubs during 488 succession. Diet ages indicate that old carbons were subsidized from belowground via 489 soil dipterans. Different spider feeding guilds segregated their food sources and diet 490 ages differently. Also, each spider feeding guild had a consistent tendency in their diet 491 age that did not show an increasing nor decreasing trend during forest succession. These 492 results indicate each predator group has consistently used either grazing or detrital prey 493 regardless of forest age. Therefore, arboreal predators may alter their assemblages based 
on changes in the availability of grazing/detrital prey during forest succession, which is

495 ultimately determined by the energy flow from grazing on detrital food chains. This

496 study highlights the importance of incorporating changes in predator community

497 composition to elucidate the dynamics of food web coupling during succession.

498

\section{Acknowledgments}

500 We thank Mr. Hajime Yamagata for facilitating our work at the OFR. Members of the

501 Community Dynamics and Insect Ecology Laboratories in the Forestry and Forest

502 Products Research Institute, particularly Dr. Takenari Inoue, provided us with site 503 information. We are also grateful for assistance from Drs. Shoji Naoe (CER), Naoto F.

504 Ishikawa (CER), and Zin'ichi Karube (NIES). This study was financially supported by 505 the Global Environment Research Fund (F-073), the Research Institute for Sustainable 506 Humanosphere, the Japan Society for the Promotion of Science (JSPS; No. 19681002, 507 22370011, 23657021) and a Grant-in-Aid for JSPS Fellows (No. 22-978).

508

\section{References}

510 Akamatsu F, Toda H, Okino T (2004) Food source of riparian spiders analyzed by using 511 stable isotope ratios. Ecol. Res. 19:655-662

512 Bardgett RD, Wardle DA (2010) Aboveground-belowground linkages: biotic 513 interactions, ecosystem processes, and global change (Oxford series in ecology and 514 evolution). Oxford University Press, New York

515 Birkhofer K, Wolters V (2012) The global relationship between climate, net primary 516 production and the diet of spiders. Glob. Ecol. Biogeogr. 21:100-108 
517 Bormann FH, Likens GE (1979) Pattern and process in a forested ecosystem. Springer

518 Verlag, New York

519 Brown KM (1981) Foraging ecology and niche partitioning in orb-weaving spiders.

520 Oecologia 50:380-385

521 Bultman TL, Uetz GW (1982) Abundance and community structure of forest floor 522 spiders following litter manipulation. Oecologia 55:34-41

523 Burchuladze AA, Chudy M, Eristavi IV, Pagava SV, Povinec P, Sivo A, Togonidze GI

524 (1989) Anthropogenic ${ }^{14} \mathrm{C}$ variations in atmospheric $\mathrm{CO}_{2}$ and wines. Radiocarbon $525 \quad 31: 771-776$

526 Chen B, Wise DH (1999) Bottom-up limitation of predaceous arthropods in a 527 detritus-based terrestrial food Web. Ecology 80:761-772

528 Coddington JA, Levi HW (1991) Systematics and evolution of spiders (Araneae). Annu. 529 Rev. Ecol. Syst. 22:565-592

530 Collier KJ, Bury S, Gibbs M (2002) A stable isotope study of linkages between stream 531 and terrestrial food webs through spider predation. Freshw. Biol. 47:1651-1659

532 Druffel EM, Griffin S (1995) Radiocarbon in tropospheric $\mathrm{CO}_{2}$ and organic materials 533 from selected northern hemisphere sites. Radiocarbon 37:883-888

534 Frouz J (1999) Use of soil dwelling Diptera (Insecta, Diptera) as bioindicators: a review

535 of ecological requirements and response to disturbance. Agric., Ecosyst. \& Environ. $536 \quad 74: 167-186$

537 Halaj J, Wise DH (2002) Impact of a detrital subsidy on trophic cascades in a terrestrial 538 grazing food web. Ecology 83:3141-3151

539 Henschel JR, Mahsberg D, Stumpf H (2001) Allochthonous aquatic insects increase 
540 predation and decrease herbivory in river shore food webs. Oikos 93:429-438

541 Hishi T, Hyodo F, Saitoh S, Takeda H (2007) The feeding habits of collembola along

542 decomposition gradients using stable carbon and nitrogen isotope analyses. Soil Biol.

543 Biochem. 39:1820-1823

544 Hyodo F, Tayasu I, Konaté S, Tondoh JE, Lavelle P, Wada E (2008) Gradual enrichment

545 of ${ }^{15} \mathrm{~N}$ with humification of diets in a below-ground food web: relationship between ${ }^{15} \mathrm{~N}$

546 and diet age determined using ${ }^{14} \mathrm{C}$. Func. Ecol. 22:516-522

547 Hyodo F, Tayasu I, Wada E (2006) Estimation of the longevity of C in terrestrial detrital

548 food webs using radiocarbon $\left({ }^{14} \mathrm{C}\right)$ : how old are diets in termites? Func. Ecol.

$549 \quad 20: 385-393$

550 Jurgensen MF, Harvey AE, Graham RT, Page-Dumroese DS, Tonn JR, Larsen MJ, Jain

551 TB (1997) Impacts of timber harvesting on soil organic matter, nitrogen, productivity,

552 and health of Inland Northwest forests. For. Sci. 43:234-251

553 Kira T, Shidei T (1967) Primary production and turnover of organic matter in different

554 forest ecosystems of the western Pacific. Japanese Journal of Ecology 17:70-87

555 Kirschbaum MUF, Paul KI (2002) Modelling C and N dynamics in forest soils with a

556 modified version of the CENTURY model. Soil Biol. Biochem. 34:341-354

557 Kitagawa H, Masuzawa T, Makamura T, Matsumoto E (1993) A batch preparation

558 method for graphite targets with low background for $\mathrm{AMS}{ }^{14} \mathrm{C}$ measurements.

559 Radiocarbon 35:295-300

560 Levin I, Hesshaimer V (2000) Radiocarbon - a unique tracer of global carbon cycle

561 dynamics. Radiocarbon 42:69-80

562 Lugo AE (2008) Visible and invisible effects of hurricanes on forest ecosystems: an 
564 McCutchan JHJ, Lewis WMJ, Kendall C, Mcgrath CC (2003) Variation in trophic shift

565 for stable isotope ratios of carbon, nitrogen, and sulfur. Oikos 102:378-390

566 Michener RH, Lajtha K (2007) Stable isotope in ecology and environmental science,

567 2nd edn. Blackwell Publishing, Malden

568 Miyashita T, Takada M, Shimazaki A (2003) Experimental evidence that aboveground

569 predators are sustained by underground detritivores. Oikos 103:31-36

570 Mizoguchi Y, Morisawa T, Ohtani Y (2002) Climate in ogawa forest reserve. In:

571 Nakashizuka T, Matsumoto Y (eds) Diversity and interaction in a temperate forest

572 community. Springer Verlag, Tokyo, pp 11-18

573 Moore JW, Semmens BX (2008) Incorporating uncertainty and prior information into

574 stable isotope mixing models. Ecol. Lett. 11:470-480

575 Moulder BC, Reichle DE (1972) Significance of spider predation in the energy

576 dynamics of forest-floor arthropod communities. Ecol. Monogr. 42:473-498

577 Pataki DE, Randerson JT, Wang W, Herzenach M, Grulke NE (2010) The carbon 578 isotope composition of plants and soils as biomarkers of pollution. In: West JB, Bowen

579 GJ, Dawson TE, Tu KP (eds) Isoscapes: Understanding Movement, Pattern, and Process

580 on Earth Through Isotope Mapping. Springer Netherlands, Dordrecht, pp 407-423

581 Pringle RM, Fox-Dobbs K (2008) Coupling of canopy and understory food webs by

582 ground-dwelling predators. Ecol. Lett. 11:1328-1337

583 R_development_core_team (2011) R: A language and environment for statistical 584 computing.

585 Rypstra AL, Marshall SD (2005) Augmentation of soil detritus affects the spider 
community and herbivory in a soybean agroecosystem. Entomolog. Experimentalis et

587 Applicata 116:149-157

588 Semmens BX, Moore JW, Ward EJ (2009) Improving Bayesian isotope mixing models:

589 a response to Jackson et al. (2009). Ecol. Lett. 12:E6-8

590 Settle WH, Ariawan H, Astuti ET, Cahyana W, Hakim AL, Hindayana D, Lestari AS

591 (1996) Managing tropical rice pests through conservation of generalist natural enemies

592 and alternative prey. Ecology 77:1975-1988

593 Shibata S, Kawano E, Nakabayashi T (2005) Atmospheric ${ }^{14} \mathrm{C} \mathrm{CO}_{2}$ variations in Japan

594 during 1982-1999 based on ${ }^{14} \mathrm{C}$ measurements of rice grains. Appl. radiat. and isotopes

$595 \quad 63: 285-290$

596 Shimazaki A, Miyashita T (2005) Variable dependence on detrital and grazing food

597 webs by generalist predators: aerial insects and web spiders. Ecography 28:485-494

598 Sork VL, Bramble J, Owen S (1993) Ecology of mast-fruiting in three species of North

599 American deciduous oaks. Ecology 74:528-541

600 Stuiver M, Polach HA (1977) Discussion: reporting of ${ }^{14} \mathrm{C}$ data. Radiocarbon $601 \quad 19: 355-363$

602 Swift MJ, Heal OW, Anderson JM (1979) Decomposition in terrestrial ecosystems.

603 University of California Press

604 Tayasu I (1998) Use of carbon and nitrogen isotope ratios in termite research. Ecol. Res.

$605 \quad 13: 377-387$

606 Tayasu I, Hyodo F (2010) Use of carbon-14 natural abundances in soil ecology:

607 implications for food web research. In: Ohkouchi N, Tayasu I, Koba K (eds) Earth, Life, 608 and Isotopes. Kyoto University Press, pp 3-16 
609 Tayasu I, Hirasawa R, Ogawa NO, Ohkouchi N, Yamada K (2011) New organic

610 reference materials for carbon- and nitrogen-stable isotope ratio measurements provided

611 by Center for Ecological Research, Kyoto University, and Institute of Biogeosciences,

612 Japan Agency for Marine-Earth Science and Technology. Limnology 12:261-266

613 Tayasu I, Nakamura T, Oda H, Hyodo F, Takematsu Y, Abe T (2002) Termite ecology in

614 a dry evergreen forest in Thailand in terms of stable $\left(\delta^{13} \mathrm{C}\right.$ and $\left.\delta^{15} \mathrm{~N}\right)$ and radio $\left({ }^{14} \mathrm{C}\right.$,

$615{ }^{137} \mathrm{Cs}$ and ${ }^{210} \mathrm{~Pb}$ ) isotopes. Ecol. Res. 17:195-206

616 Uchida M, Shibata Y, Yoneda M, Kobayashi T, Masatoshi M (2004) Technical progress

617 in AMS microscale radiocarbon analysis. Nucl. Instrum. Methods in Phys. Res. Section

618 B: Beam Interact. Mater. Atoms 223-224:313-317

619 Uetz GW, Halaj J, Cady AB (1999) Guild structure of spiders in major crops. Journal of 620 Arachnol. 27:270-280

621 Vander Zanden MJ, Vadeboncoeur Y (2002) Fishes as integrators of benthic and pelagic 622 food webs in lakes. Ecology 83:2152-2161

623 Von Berg K, Thies C, Tscharntke T, Scheu S (2010) Changes in herbivore control in 624 arable fields by detrital subsidies depend on predator species and vary in space. 625 Oecologia 163:1033-1042

626 Wardle DA, Bardgett RD, Klironomos JN, Setälä H, van der Putten WH, Wall DH 627 (2004) Ecological linkages between aboveground and belowground biota. Science $628 \quad 304: 1629-1633$ 


\section{$630 \quad$ Figure legends}

631 Fig. 1 Carbon and nitrogen stable isotope biplots of arboreal prey categories

632 (Collembola, Hemiptera and larval Lepidoptera), aerial prey (Diptera) and arboreal

633 spiders in (a) 1-, (b) 7-, (c) 11-, (d) 24-, and (e) 105-year-old sites. Isotope ratios of prey

634 are shown with the mean \pm standard deviation, whereas those of spiders were offset by

635 the trophic enrichment factor $\left(0.5 \%\right.$ for $\delta^{13} \mathrm{C}$ and $2.3 \%$ for $\left.\delta^{15} \mathrm{~N}\right)$ and shown

636 individually. Data sets shown in the figure were applied to the MixSIR source mixing

637 model (see materials and methods).

638

639 Fig. 2 (a) $\Delta^{14} \mathrm{C}$ values of leaves of dominant tree species (see $\mathrm{S} 1$ for sample

640 composition) and (b) diet ages of the two spider species (Yaginumaella striatipes and

641 Leucauge subblanda) with calibration of foliar $\Delta^{14} \mathrm{C}$ means at every study site. Labels

642 on the $\mathrm{x}$ axis indicate stand ages of study sites in which the samples were collected.

643 Bars indicate means \pm standard deviations.

644

645 Fig. 3 Diet ages of arboreal prey categories (Collembola, Hemiptera and larval

646 Lepidoptera), aerial prey (Diptera) and arboreal spiders. Labels of the lateral axis

647 indicate stand ages of study sites at which the samples were collected. Bars indicate

648 means \pm standard deviations.

649

650 Fig. 4. Relationships between diet ages of spiders and (a) the relative contribution of

651 aerial prey (b) $\delta^{13} \mathrm{C}$ (c) $\delta^{15} \mathrm{~N}$. Lines in (a) to (c) indicate statistically significant linear 652 regression $(n=51)$. 


\section{Figures}

Fig. 1

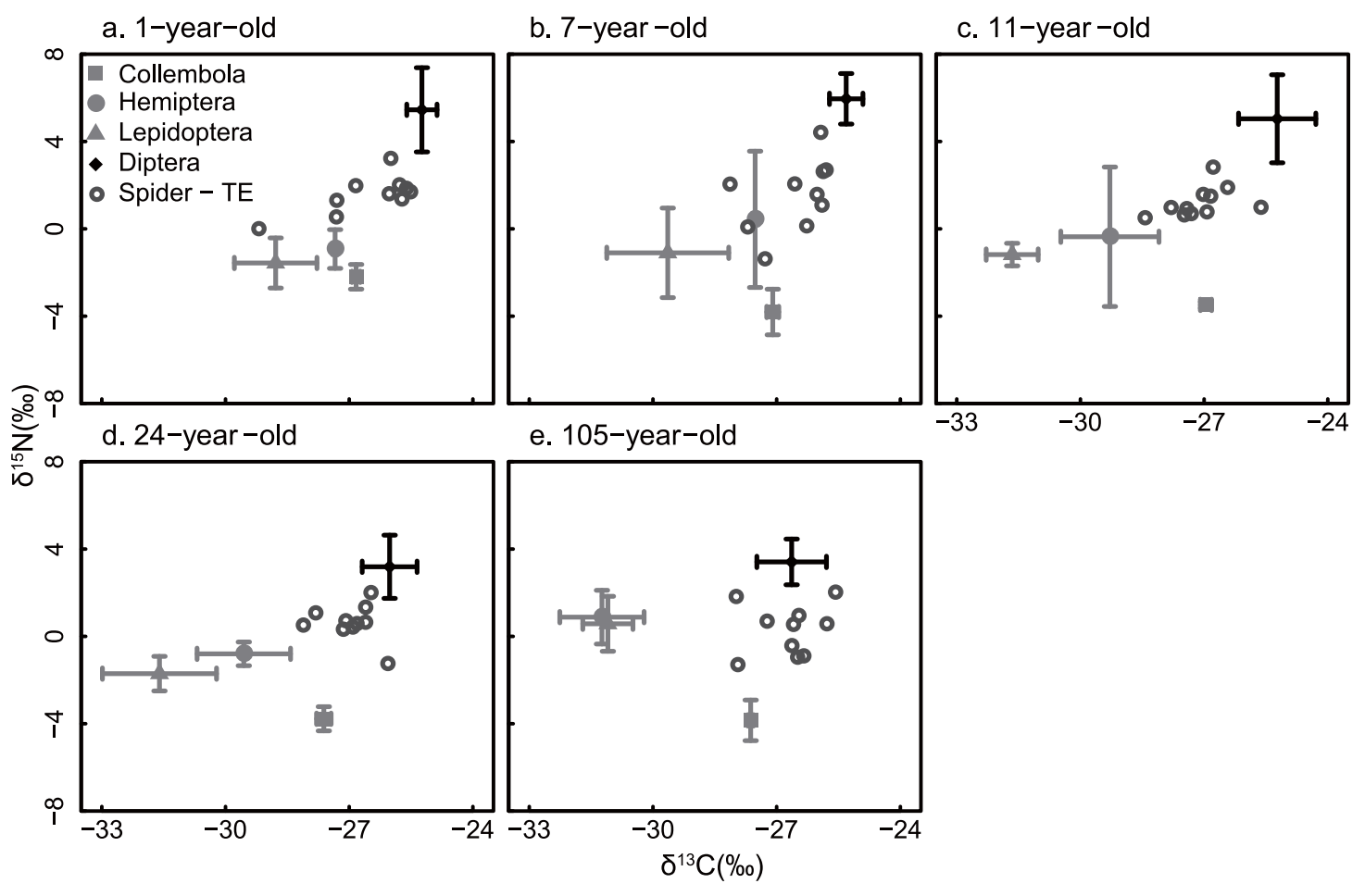


Fig. 2
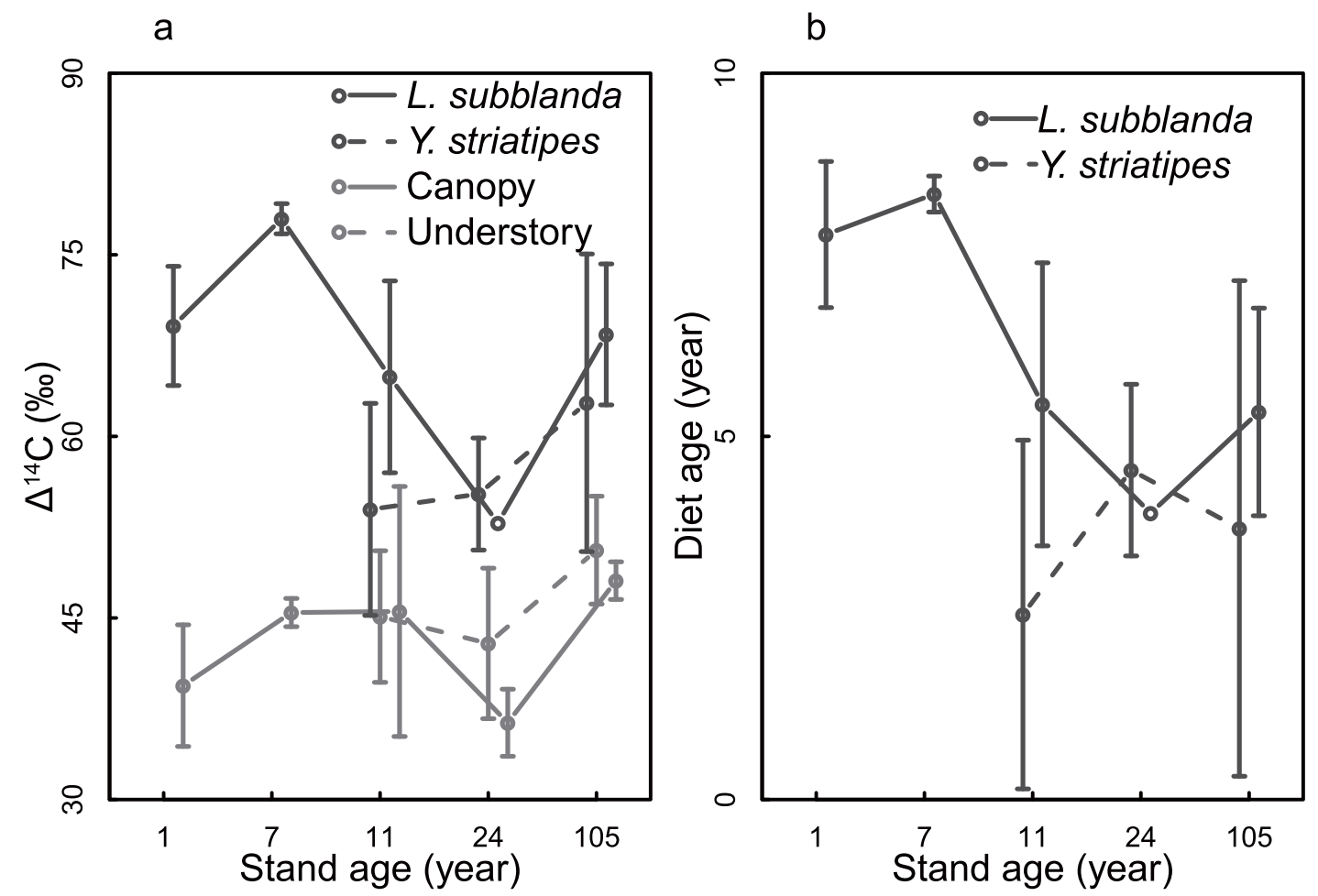
Fig. 3

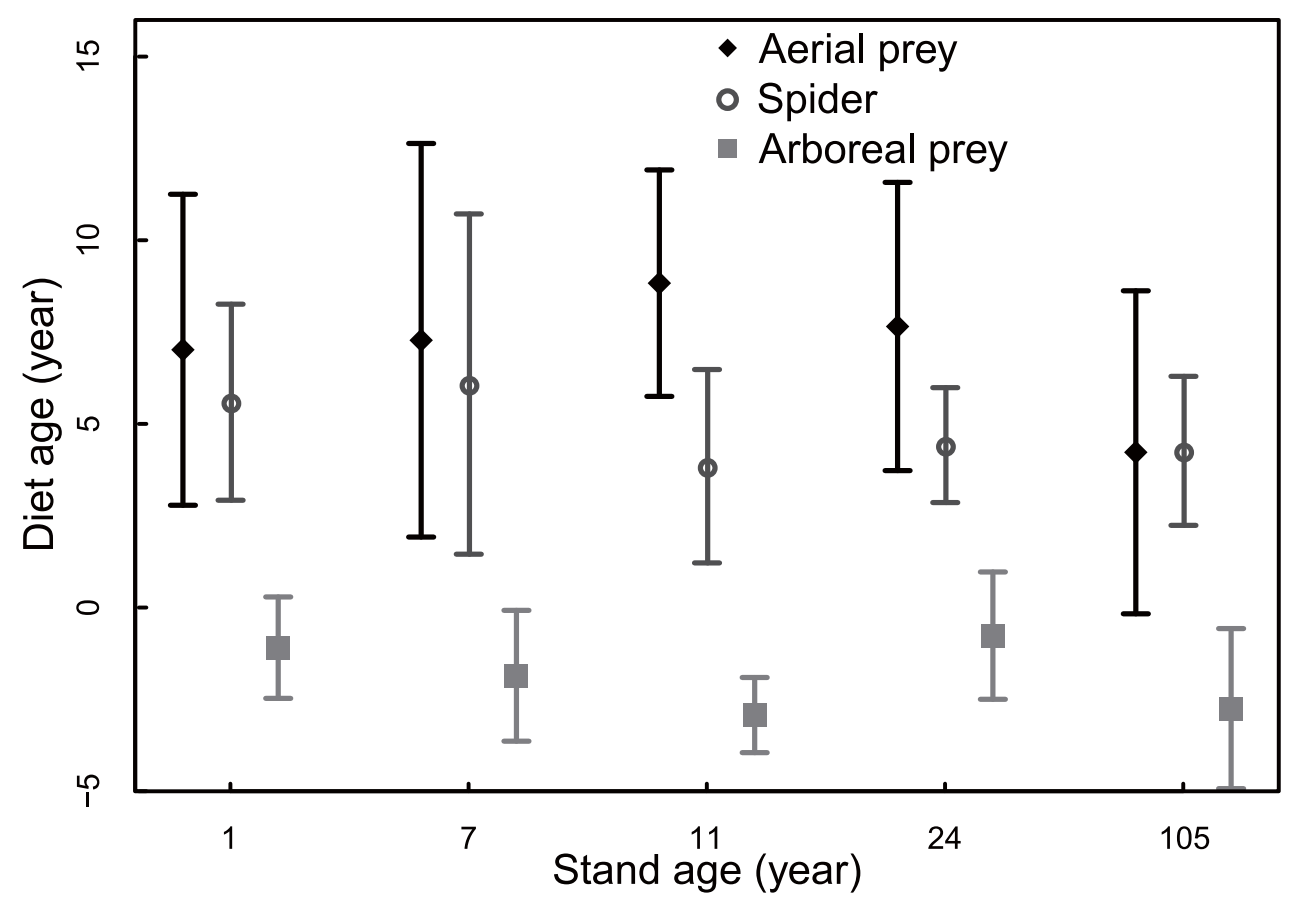


Fig. 4

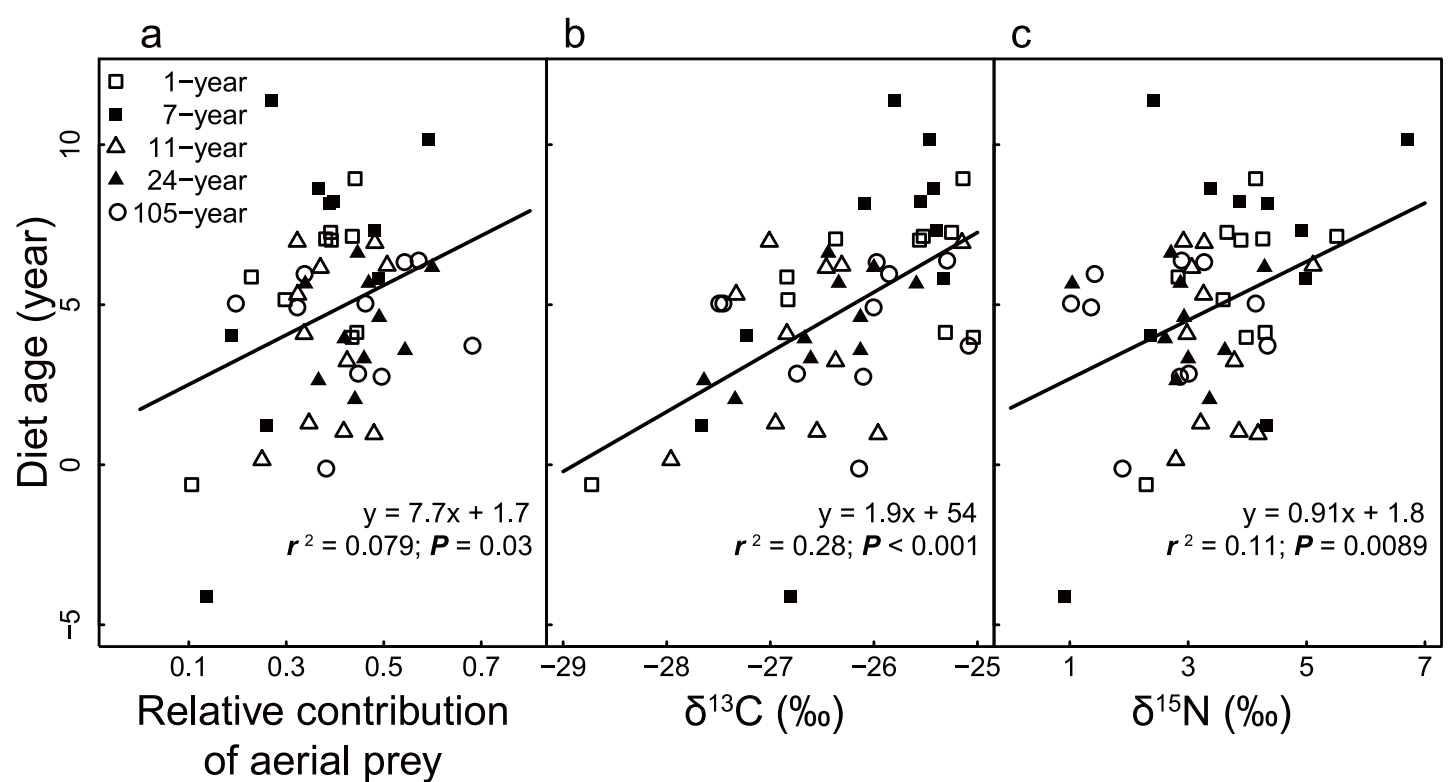




\section{Contributions of detrital subsidies to aboveground spiders} during secondary succession, revealed by radiocarbon and

\section{stable isotope signatures}

Takashi F. Haraguchi*a, Masao Uchida ${ }^{\mathrm{b}}$, Yasuyuki Shibata ${ }^{\mathrm{b}}$ and Ichiro Tayasu ${ }^{\mathrm{a}}$

${ }^{a}$ Center for Ecological Research, Kyoto University, 2-509-3 Hirano, Otsu, Shiga 5202113, Japan

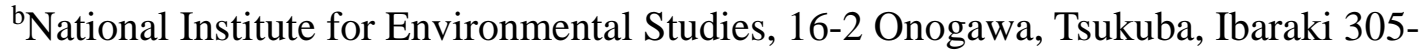
8506, Japan

*Corresponding author: takashih@ecology.kyoto-u.ac.jp

Electronic supplementary material (ESM) 
Appendix S1. Measured values and attributes of isotope samples of fresh leaves.

Sampling sites were named for the stand age (years after clear-cutting).

\begin{tabular}{cccccc}
$\begin{array}{c}\text { Sampling } \\
\text { site }\end{array}$ & Species & Canopy/understory & $\begin{array}{c}\delta^{13} \mathrm{C} \\
(\%)\end{array}$ & $\begin{array}{c}\delta^{15} \mathrm{~N} \\
(\%)\end{array}$ & $\begin{array}{c}\Delta^{14} \mathrm{C} \\
(\% \circ)\end{array}$ \\
\hline 1-year & Quercus serrata & canopy & -28.4 & 0.1 & 42.3 \\
1-year & Quercus serrata & canopy & -28.7 & 1.3 & 33.6 \\
1-year & Quercus serrata & canopy & -28.9 & 1.6 & 42.3 \\
7-year & Cletha barvinervis & canopy & -29.4 & -0.9 & 46.3 \\
7-year & Cletha barvinervis & canopy & -29.8 & -0.9 & 44.1 \\
7-year & Cletha barvinervis & canopy & -30.4 & -1.0 & 46.0 \\
11-year & Castanea crenata & canopy & -31.0 & -1.8 & 47.9 \\
11-year & Castanea crenata & canopy & -31.2 & -1.5 & 34.3 \\
11-year & Castanea crenata & canopy & -28.1 & -1.7 & 54.5 \\
11-year & Prunus grayana & understory & -29.7 & -3.1 & 44.2 \\
11-year & Prunus grayana & understory & -30.9 & -2.6 & 51.0 \\
11-year & Prunus grayana & understory & -30.0 & -1.7 & 40.2 \\
24-year & Castanea crenata & canopy & -29.9 & -1.6 & 34.0 \\
24-year & Castanea crenata & canopy & -30.7 & -1.1 & 35.6 \\
24-year & Castanea crenata & canopy & -30.7 & -1.0 & 39.4 \\
24-year & Hydrangea paniculata & understory & -30.2 & -1.6 & 38.1 \\
24-year & Hydrangea paniculata & understory & -30.4 & -1.0 & 40.6 \\
24-year & Hydrangea paniculata & understory & -31.7 & -2.0 & 49.9 \\
105-year & Quercus serrata & canopy & -30.7 & -2.4 & 46.4 \\
105-year & Quercus serrata & canopy & -29.5 & -2.3 & 48.4 \\
105-year & Quercus serrata & canopy & -28.5 & -0.6 & 49.5 \\
105-year & Fagus crenata & understory & -31.8 & -1.8 & 46.0 \\
105-year & Fagus crenata & understory & -32.2 & -0.3 & 50.9 \\
105-year & Fagus crenata & understory & -32.6 & -0.1 & 54.9
\end{tabular}


Appendix S2. Measured values and attributes of isotope samples of spiders. Sampling sites were named for the stand age (years after clear-cutting). Sampling site, species and feeding guild shown in the table were used as explanatory variables for the analyses of isotopic values and diet ages.

\begin{tabular}{|c|c|c|c|c|c|c|}
\hline $\begin{array}{c}\text { Sampling } \\
\text { site }\end{array}$ & Species & Feeding guild & $\begin{array}{l}\delta^{13} \mathrm{C} \\
(\% \circ) \\
\end{array}$ & $\begin{array}{l}\delta^{15} \mathrm{~N} \\
(\% \circ)\end{array}$ & $\begin{array}{r}\Delta^{14} \mathrm{C} \\
(\%)\end{array}$ & $\begin{array}{c}\text { Diet age } \\
\text { (year) }\end{array}$ \\
\hline 1-year & Araneus macacus & Orb web & -26.4 & 4.3 & 65.6 & 7.0 \\
\hline 1-year & Argiope bruennichi & Orb web & -25.0 & 4.0 & 52.8 & 4.0 \\
\hline 1-year & Carrhotus xanthogramma & Visual pursuit & -26.8 & 3.6 & 57.4 & 5.1 \\
\hline 1-year & Cheiracanthium japonicum & Nocturnal & -28.7 & 2.3 & 37.6 & -0.6 \\
\hline 1-year & Diaea subdola & Crab & -26.8 & 2.8 & 60.4 & 5.8 \\
\hline 1-year & Leucauge subblanda & Orb web & -25.5 & 5.5 & 66.0 & 7.1 \\
\hline 1-year & Leucauge subblanda & Orb web & -25.1 & 4.1 & 74.8 & 8.9 \\
\hline 1-year & Leucauge subblanda & Orb web & -25.3 & 3.7 & 66.6 & 7.2 \\
\hline 1-year & Leucauge subgemmea & Orb web & -25.6 & 3.9 & 65.4 & 7.0 \\
\hline 1-year & Neoscona adianta & Orb web & -25.3 & 4.3 & 53.4 & 4.1 \\
\hline 7-year & Araneus stella & Orb web & -27.7 & 4.3 & 49.2 & 1.2 \\
\hline 7-year & Carrhotus xanthogramma & Visual pursuit & -27.2 & 2.4 & 59.1 & 4.0 \\
\hline 7-year & Cyclosa hamulata & Orb web & -25.5 & 6.7 & 87.7 & 10.1 \\
\hline 7-year & Leucauge subblanda & Orb web & -25.4 & 3.4 & 79.4 & 8.6 \\
\hline 7-year & Leucauge subblanda & Orb web & -25.5 & 3.9 & 77.5 & 8.2 \\
\hline 7-year & Leucauge subblanda & Orb web & -26.1 & 4.3 & 77.1 & 8.1 \\
\hline 7-year & Leucauge subgemmea & Orb web & -25.8 & 2.4 & 94.7 & 11.4 \\
\hline 7-year & Oxytate striatipes & Crab & -25.4 & 4.9 & 73.1 & 7.3 \\
\hline 7-year & Tetragnatha yesoensis & Orb web & -25.3 & 5.0 & 66.4 & 5.8 \\
\hline 7-year & Trachelas japonicus & Nocturnal & -26.8 & 0.9 & 34.7 & -4.1 \\
\hline 11-year & Clubiona rostrata & Nocturnal & -26.8 & 3.0 & 59.2 & 4.1 \\
\hline 11-year & Leucauge subblanda & Orb web & -26.5 & 3.1 & 67.6 & 6.1 \\
\hline 11-year & Leucauge subblanda & Orb web & -26.4 & 3.8 & 56.0 & 3.2 \\
\hline 11-year & Leucauge subblanda & Orb web & -25.2 & 3.3 & 71.1 & 6.9 \\
\hline 11-year & Menosira ornata & Orb web & -28.0 & 2.8 & 45.8 & 0.1 \\
\hline 11-year & Oxytate striatipes & Crab & -26.3 & 5.1 & 67.9 & 6.2 \\
\hline 11-year & Plexippides doenitzi & Visual pursuit & -26.0 & 4.2 & 48.3 & 1.0 \\
\hline 11-year & Tetragnatha yesoensis & Orb web & -27.0 & 2.9 & 71.3 & 7.0 \\
\hline 11-year & Yaginumaella striatipes & Visual pursuit & -26.5 & 3.9 & 48.5 & 1.0 \\
\hline 11-year & Yaginumaella striatipes & Visual pursuit & -27.3 & 3.3 & 64.1 & 5.3 \\
\hline 11-year & Yaginumaella striatipes & Visual pursuit & -26.9 & 3.2 & 49.3 & 1.3 \\
\hline
\end{tabular}




\begin{tabular}{|c|c|c|c|c|c|c|}
\hline $\begin{array}{l}\text { Sampling } \\
\text { site }\end{array}$ & Species & Feeding guild & $\begin{array}{c}\delta^{13} \mathrm{C} \\
(\% \circ)\end{array}$ & $\begin{array}{c}\delta^{15} N \\
(\% \circ)\end{array}$ & $\begin{array}{c}\Delta^{14} \mathrm{C} \\
(\% \text { o })\end{array}$ & $\begin{array}{c}\text { Diet age } \\
\text { (year) }\end{array}$ \\
\hline 24-year & Araneus stella & Orb web & -27.3 & 3.4 & 46.1 & 2.0 \\
\hline 24-year & Clubiona japonica & Nocturnal & -25.6 & 1.0 & 59.7 & 5.6 \\
\hline 24-year & Leucauge subblanda & Orb web & -26.7 & 2.6 & 52.8 & 3.9 \\
\hline 24-year & Menosira ornata & Orb web & -27.6 & 2.8 & 48.1 & 2.6 \\
\hline 24-year & Oxytate striatipes & Crab & -26.0 & 4.3 & 61.9 & 6.1 \\
\hline 24-year & Plexippides doenitzi & Visual pursuit & -26.1 & 3.6 & 51.5 & 3.6 \\
\hline 24-year & Tetragnatha yesoensis & Orb web & -26.4 & 2.7 & 63.8 & 6.6 \\
\hline 24-year & Yaginumaella striatipes & Visual pursuit & -26.1 & 2.9 & 55.4 & 4.6 \\
\hline 24-year & Yaginumaella striatipes & Visual pursuit & -26.3 & 2.9 & 59.8 & 5.6 \\
\hline 24-year & Yaginumaella striatipes & Visual pursuit & -26.6 & 3.0 & 50.5 & 3.3 \\
\hline 105-year & Clubiona rostrata & Nocturnal & -26.8 & 3.0 & 58.6 & 2.8 \\
\hline 105-year & Leucauge subblanda & Orb web & -25.9 & 1.4 & 70.8 & 6.0 \\
\hline 105-year & Leucauge subblanda & Orb web & -25.3 & 2.9 & 72.7 & 6.4 \\
\hline 105-year & Leucauge subblanda & Orb web & -25.1 & 4.3 & 61.8 & 3.7 \\
\hline 105-year & Neoscona scylla & Orb web & -27.5 & 4.1 & 66.9 & 5.0 \\
\hline 105-year & Oxytate striatipes & Crab & -26.1 & 2.8 & 58.2 & 2.7 \\
\hline 105-year & Tetragnatha yesoensis & Orb web & -26.0 & 1.3 & 66.5 & 4.9 \\
\hline 105-year & Yaginumaella striatipes & Visual pursuit & -26.2 & 1.9 & 48.9 & -0.1 \\
\hline 105-year & Yaginumaella striatipes & Visual pursuit & -27.5 & 1.0 & 66.9 & 5.0 \\
\hline 105-year & Yaginumaella striatipes & Visual pursuit & -26.0 & 3.2 & 72.4 & 6.3 \\
\hline
\end{tabular}


Appendix S3. Measured values and attributes of isotope samples of prey. Diptera

samples were divided by body length; the "size faction" column gives the size ranges.

Sampling sites were named for the stand age (years after clear-cutting). "-" indicates the item was not measured.

\begin{tabular}{|c|c|c|c|c|c|}
\hline $\begin{array}{l}\text { Sampling } \\
\text { site }\end{array}$ & Prey category & $\begin{array}{c}\delta^{13} \mathrm{C} \\
(\% \circ)\end{array}$ & $\begin{array}{c}\delta^{15} \mathrm{~N} \\
(\% \circ)\end{array}$ & $\begin{array}{c}\Delta^{14} \mathrm{C} \\
(\% \circ)\end{array}$ & $\begin{array}{c}\text { Diet age } \\
\text { (year) }\end{array}$ \\
\hline 1-year & Collembola & -26.8 & -2.8 & 35.5 & -1.4 \\
\hline 1-year & Collembola & -26.8 & -2.0 & - & - \\
\hline 1-year & Collembola & -26.6 & -1.8 & - & - \\
\hline 1-year & Diptera $0-5 \mathrm{~mm}$ & -25.4 & 6.3 & 56.0 & 4.8 \\
\hline 1-year & Diptera $5-10 \mathrm{~mm}$ & -25.3 & 6.8 & 54.2 & 4.3 \\
\hline 1-year & Diptera 10- $\mathrm{mm}$ & -24.7 & 3.2 & 91.6 & 11.8 \\
\hline 1-year & Hemiptera & -27.3 & -1.9 & 40.6 & 0.4 \\
\hline 1-year & Hemiptera & -27.2 & -0.3 & - & - \\
\hline 1-year & Hemiptera & -27.4 & -0.5 & - & - \\
\hline 1-year & Lepidoptera larvae & -30.0 & -0.3 & 33.1 & -2.3 \\
\hline 1-year & Lepidoptera larvae & -28.1 & -2.4 & - & - \\
\hline 1-year & Lepidoptera larvae & -28.2 & -2.0 & - & - \\
\hline 7-year & Collembola & -26.9 & -3.6 & 40.3 & -1.8 \\
\hline 7-year & Collembola & -27.2 & -5.0 & - & - \\
\hline 7-year & Collembola & -27.0 & -2.9 & - & - \\
\hline 7-year & Diptera $0-5 \mathrm{~mm}$ & -25.1 & 5.5 & 93.5 & 11.2 \\
\hline 7-year & Diptera $5-10 \mathrm{~mm}$ & -25.6 & 5.1 & 49.1 & 1.2 \\
\hline 7-year & Diptera 10- $\mathrm{mm}$ & -24.8 & 7.3 & 84 & 9.5 \\
\hline 7-year & Hemiptera & -27.5 & -1.8 & 35.7 & -3.6 \\
\hline 7-year & Hemiptera & -27.4 & 2.6 & - & - \\
\hline 7-year & Lepidoptera larvae & -31.4 & 1.3 & 45.2 & -0.1 \\
\hline 7-year & Lepidoptera larvae & -28.5 & -2.2 & - & - \\
\hline 7-year & Lepidoptera larvae & -29.1 & -2.4 & - & - \\
\hline 11-year & Collembola & -27.0 & -3.4 & 38.6 & -2.4 \\
\hline 11-year & Collembola & -26.8 & -3.6 & - & - \\
\hline 11-year & Diptera $0-5 \mathrm{~mm}$ & -25.8 & 3.9 & 72.4 & 7.2 \\
\hline 11-year & Diptera $5-10 \mathrm{~mm}$ & -25.5 & 3.8 & 71.0 & 6.9 \\
\hline 11-year & Diptera 10- $\mathrm{mm}$ & -24.0 & 7.4 & 100.9 & 12.4 \\
\hline 11-year & Hemiptera & -30.7 & -2.8 & 34.6 & -4.1 \\
\hline 11-year & Hemiptera & -28.4 & -1.6 & - & - \\
\hline 11-year & Hemiptera & -28.9 & 3.3 & - & - \\
\hline 11-year & Lepidoptera larvae & -31.0 & -1.5 & 39.1 & -2.2 \\
\hline 11-year & Lepidoptera larvae & -32.3 & -0.6 & - & - \\
\hline 11-year & Lepidoptera larvae & -32.0 & -1.4 & - & - \\
\hline
\end{tabular}


Appendix S3 continued

\begin{tabular}{|c|c|c|c|c|c|}
\hline $\begin{array}{c}\text { Sampling } \\
\text { site }\end{array}$ & Prey category & $\begin{array}{c}\delta^{13} \mathrm{C} \\
(\% \circ)\end{array}$ & $\begin{array}{c}\delta^{15} N \\
(\% \circ)\end{array}$ & $\begin{array}{c}\Delta^{14} \mathrm{C} \\
(\% \circ)\end{array}$ & $\begin{array}{c}\text { Diet age } \\
\text { (year) }\end{array}$ \\
\hline 24-year & Collembola & -27.8 & -4.4 & 41.7 & 0.7 \\
\hline 24-year & Collembola & -27.5 & -3.4 & - & - \\
\hline 24-year & Collembola & -27.4 & -3.5 & - & - \\
\hline 24-year & Diptera $0-5 \mathrm{~mm}$ & -26.2 & 4.9 & 67.6 & 7.4 \\
\hline 24-year & Diptera $5-10 \mathrm{~mm}$ & -26.5 & 2.8 & 52.5 & 3.8 \\
\hline 24-year & Diptera 10- $\mathrm{mm}$ & -26.1 & 1.4 & 90.5 & 11.6 \\
\hline 24-year & Hemiptera & -30.5 & -1.3 & 38.7 & -0.3 \\
\hline 24-year & Hemiptera & -28.3 & -0.2 & - & - \\
\hline 24-year & Hemiptera & -30.0 & -0.8 & - & - \\
\hline 24-year & Lepidoptera larvae & -31.9 & -1.3 & 32.3 & -2.7 \\
\hline 24-year & Lepidoptera larvae & -33.1 & -2.6 & - & - \\
\hline 24-year & Lepidoptera larvae & -30.2 & -1.2 & - & - \\
\hline 105-year & Collembola & -27.7 & -4.5 & 38.1 & -4.3 \\
\hline 105-year & Collembola & -27.5 & -3.2 & - & - \\
\hline 105-year & Diptera $0-5 \mathrm{~mm}$ & -25.6 & 3.7 & 78.0 & 7.5 \\
\hline 105-year & Diptera $5-10 \mathrm{~mm}$ & -26.8 & 4.3 & 47.1 & -0.8 \\
\hline 105-year & Diptera 10- $\mathrm{mm}$ & -27.3 & 2.3 & 70.8 & 5.9 \\
\hline 105-year & Hemiptera & -30.2 & 0.1 & 48.6 & -0.3 \\
\hline 105-year & Hemiptera & -31.5 & 0.2 & - & - \\
\hline 105-year & Hemiptera & -32.4 & 2.3 & - & - \\
\hline 105-year & Lepidoptera larvae & -30.6 & 1.6 & 39.6 & -3.7 \\
\hline 105-year & Lepidoptera larvae & -31.2 & -0.8 & - & - \\
\hline 105-year & Lepidoptera larvae & -31.8 & 0.9 & - & - \\
\hline
\end{tabular}

